\title{
Synthesis of Ag-NPs from extracts of Persea americana and its antimicrobial effects in human pathogens
}

\author{
K.A. Selvam 1, *, M. Suriyakumar ${ }^{1}$, J. Devanathan ${ }^{1}$, K. Kolanjinathan ${ }^{2}$, A. Ram kumar ${ }^{3}$, \\ S. Selvaraj ${ }^{4}$, L. Ramadass ${ }^{5}$
}

${ }^{1}$ PG and Research Department of Microbiology, Indo - American College, Cheyyar - 604407, Tamil Nadu, India.
2 Department of Microbiology, Faculty of Science, Annamalai University, Annamalai Nagar, Chidambaram - 608002
${ }^{3}$ PG and Research Department of Biochemistry, Indo - American College, Cheyyar - 604407, Tamil Nadu, India.
${ }^{4}$ Department of Physics, Indo - American College, Cheyyar - 604407, Tamil Nadu, India.
${ }^{5}$ Department of Chemistry, Indo - American College, Cheyyar - 604407, Tamil Nadu, India
${ }^{*}$ Corresponding author Email: selvamchinna20@gmail.com

DOI: https://doi.org/10.34256/nnxt2012

Received: 09-11-2020; Accepted: 12-11-2020; Published: 13-11-2020

Abstract: Medicines of plant origin have been used to combat human diseases since time immemorial even before the history of their documentation. They have been used by human beings since time immemorial for curing health. The phytochemical screening of leaf extracts of Persea americanashows the presence of alkaloids, flavanoids, carbohydrates, saponins, protein, tannins and glycoside. Also the synthesis of silver nanoparticles was done using ethanolic Persea americana leaf extract. The synthesized silver nanoparticles were characterized by using Ultraviolet- visible (UV-Vis) spectroscopy, X-ray diffraction analysis (XRD), scanning electron microscopy (SEM) and Fourier transform infrared (FT-IR) analysis. The antimicrobial potential of synthesized nanoparticles was determined on the basis of mean diameter of zone of inhibition around the disc in millimeters. The antibacterial activity was evaluated qualitatively through agar disc diffusion towards Lactobacillus $s p$, Staphylococcus aureus, Streptococcus mutans, Klebsiella pneumoniae, Serratia marcescens, and Escherichia coli. The highest zone of inhibition value $(15.0 \mathrm{~mm})$ in Streptococcus mutans $15 \pm 0.6$. The antifungal activity against Aspergillus niger, Aspergillus flaves, Candida albicans and Fusarium sp. From the results, excellent and eco-friendly green source for production of potential bio antimicrobial silver nanoparticles.

Keywords: Persea americana, Phytochemicals, Silver nanoparticles, Antimicrobial activity

\section{Introduction}

Medicinal plants are potential source of therapeutic uses in many countries due to less toxic and side effect when compare with synthetic drugs. Persea americana is commonly known as avocado, found in tropical and subtropical countries, the parts of Persea americana widely used as traditional medicines [1]. The fruit of Persea americana have been rich in nutrients, vitamins ( $B, K$ and $E$ ) and minerals such as potassium and magnesium [2]. The leaves of Persea americana have many biological properties such as antidiabetic, antihypertensive and antiinflammatory activities [3, 4]. The leaf of Persea americana is also used to control and treatment of epilepsy in some rural countries [5]. Adeboye and his co-workers reported that aqueous leaf extract of Persea americana shows hypotensive activity in dose dependent manner in rats [6]. The methanolic leaf extract of $P$. americana significantly induced the activity of enzymatic antioxidants such as superoxide dismutase (SOD), catalase (CAT) and glutathione peroxidase (GPx) during hepatic damage produced by paracetamol [7]. By transesterification reaction production of biodiesel from avocado plant was reported by Paul and Adewale [8]. The leaf extract of Persea americana exhibits antiviral activity against adenoviruse and human immunodeficiency virus (HIV) $[9,10]$. Bartholomew and his co-workers reported that methanolic and aqueous leaf extract of Persea americana decrease the blood glucose and bad cholesterol LDL level and increase the good cholesterol HDL level to minimize the risk of atherosclerosis [11].

The core aim of the present investigation was to determine the biological applications such as antibacterial and antifungal activities and also to determine the secondary metabolites present in ethanolic leaf extract of Persea americana. 


\section{Materials and methods}

\subsection{Collection of bacterial and fungal culture}

The bacterial and fungal cultures were obtained from Dr. S. Rajeshkumar,young scientist (DST-SERB) department of pharmacology, Saveetha Dental College \& Hospital, Chennai-600 077.

\subsubsection{Bacterial cultures}

Staphylococcusaureus, Streptococcusmutans, Escherichiacoli, Lactobacillus, Klebsiella pneumonia and Serratiae marcescens

\subsubsection{Fungal culture}

Fusarium, Candidaalbicanus,Aspergillusniger and Aspergillus flavus

\subsubsection{Maintenance of bacterial and fungal culture}

The bacterial and fungal cultures were subcultures and maintained on nutrient slant and Sabouraud dextrose agar stored in refrigerator at $4^{\circ} \mathrm{C}$.

\subsubsection{Bacterial inoculum preparation}

Bacterial inoculums were prepared by inoculating a loopful of organism in $5 \mathrm{ml}$ of nutrient broth and incubated at $37^{\circ} \mathrm{C}$ for 12 hours till moderate turbidity was developed. The turbidity was maintained with 0.5 McFarland standards and then used for the determination of antimicrobial activity.

\subsection{Sample collection}

The Persea americana (avocado) leaves were collected from a Mysore, Karnataka state, India, in the month of July -2019 .

\subsection{Preparation of leaf extract}

The leaves were washed with distilled water to remove dirt and soil materials, it was separated into small pieces by a table knife and dried under shade at room temperature. The dried plant part was separately crushed into fine powder using milling machine and mortar pestle. The crude extract was of $50 \mathrm{gram}$ of the powdered material was using $150 \mathrm{ml}$ of solventsuccessively obtained by Soxhlet extraction method at the temperature not exceeding $45-55^{\circ} \mathrm{C}$. The content of each flask were subjected to reflux, below the boiling point of the respective solvent (Ethanol78\%) for 6-8 hours in order to solublize the active compounds into the solvent. The pooled extracts were individually concentrated by removing the solvent under reduced temperatures using vacuum rotator evaporator. These extract were further concentrated by solvent evaporation using thin film method. The extract was stored in a refrigerator at $4^{\circ} \mathrm{C}$ for further study.

\subsection{Phytochemicals screening}

The Phytochemical analysis was carried out using ethanolic leaf extract of Persea americana, with standard procedure described by Harborne et al., 1973 [12]. The presence of phytochemicals such as alkaloids, flavonoids, proteins, carbohydrates, tannins, glycosides, saponins, terpenoids and anthroquinone were tested.

\subsection{Synthesis of silver nanoparticles}

Silver nanoparticles were synthesized using 5 $\mathrm{mM}$ of silver nitrate $(0.017 \mathrm{~g})$ was dissolved in $180 \mathrm{ml}$ of distilled water and stirred for few minutes. $20 \mathrm{ml}$ of the ethanol leaf extract was added with $80 \mathrm{ml}$ of silver nitrate. Kept under magnetic stirrer at $60^{\circ} \mathrm{C}$ for 6 hrs at the end dark brown colour was appeared, which indicated the reduction of silver nanoparticles. The product was washed with deionized water and dried in hot air oven at $80-100^{\circ} \mathrm{C}$ for $3 \mathrm{hrs}$. The dried power was stored and used for further analysis.

\subsection{Characterization of silver nanoparticles}

The synthesized silver ions were optically determined using UV-vis spectroscopy in the range between 200 to $800 \mathrm{~nm}$ using Shimadzu (model UV2480) spectrophotometer. The Fourier transform infrared spectroscopy FTIR was done in the range $4000-400 \mathrm{~cm}^{-1}$ using an (Affinity-1, Schimadzu) spectrometer and $\mathrm{KBr}$ pellet 4000 to $400 \mathrm{~cm}^{-1}$. The morphological and crystalline structure of synthesized nanoparticle was analysed by XRD in $2 \theta$ and the scanning range was done between $10^{\circ}$ to $90^{\circ}$.

\subsection{Antimicrobial activity}

\subsubsection{Disc diffusion method}

Antimicrobial activities of the extract were screened by the agar disc diffusion method. It is grown in bacterial and fungal cultures, which were adjusted to $10^{-8} \mathrm{CFU} / \mathrm{ml}$ respectively. Then, $100 \mu \mathrm{l}$ cell suspensions were spread on the surface of MullerHinton agar plates. The discs ( $6 \mathrm{~mm}$ in diameter) were impregnated with $10 \mu \mathrm{l}$ of the extract as $30 \mu \mathrm{g}$ per disc 
and placed on the inoculated media. The petridishes were allowed to stand for $2 \mathrm{hrs}$ at $4^{\circ} \mathrm{C}$ for diffusion of the metabolites and then incubated at $37^{\circ} \mathrm{C}$ for $24 \mathrm{hrs}$ for bacteria and $26 \pm 1^{\circ} \mathrm{C}$ for 48 to 72 hrs for fungi. Antimicrobial activity was determined by measuring the radius of the clear inhibition zone around each disc.

\subsubsection{Well diffusion method}

Known quantity of the extract was dissolved in solvents, Acetone and Methanol of 1:1 ratio and then the extract was used for the next level process. The petriplates containing $20 \mathrm{ml}$ Muller-Hinton agar and Sabouraud dextrose agar were seeded with the 24 hours cultures of the strains. Wells were made with sterile cork borerand $20 \mu \mathrm{l}$ of the extract were added. The plates were then incubated at $37^{\circ} \mathrm{C}$ for 24 hours. The antimicrobial activity was assayed by measuring the diameter of the inhibition zone formed around the well (NCCLS).

\section{Results and discussion}

\subsection{Phytochemical analysis}

Secondary metabolites in the plants such as alkaloids, flavonoids, tannins and terpenoids play crucial role in the series of biological activities like antimicrobial, antidiabetic, antiinflammatory and antioxidant properties. From the present investigation, the ethanolic leaf extract of Persea americana contains alkaloids, flavonoids, carbohydrates, glycosides, saponins, tannins, proteins and absence of terpenoids and anthroquinone and the data were presented in the Table 1.

\subsection{Silver nanoparticles synthesis}

Initially the colourless silver solution was turned to brown after the addition of ethanolic leaf extract Persea americana, which confirms the synthesis of silver nanoparticle in the solution. By increasing the concentration of the extract, the rate of reduction of silver also increased and gives dark brown colour appearance. The colour change was shown in the Fig. 1. It is also confirmed by UV-visible analysis by producing a strong peak at $428 \mathrm{~nm}$ in the absorption spectra, is the characteristic peak of silver nanoparticles, which was also shown in the Fig. 2. After the conformation, the solution was centrifuged at $5000 \mathrm{rpm}$ for 15 minutes and the pellet was collected and washed with deionized water and dried in hot air oven $80-100^{\circ} \mathrm{C}[13]$.
Table 1 Phytochemical analysis of Persea americana ethanolic extract

\begin{tabular}{|l|l|l|}
\hline S.No & Test/leaves extract & Ethanol \\
\hline 1. & Test for Alkaloids & \\
\hline & A)Mayer's test & + \\
\hline & b)Warner's test & + \\
\hline & C)Dragendroff's test & + \\
\hline 2. & Test for Flavonoids & \\
\hline & a)Shinoda test & + \\
\hline & b)Alkaline reagent & + \\
\hline 3. & Test for Carbohydrates & \\
\hline & a)Benedict's test & + \\
\hline & b)Molish's test & - \\
\hline 4. & Test for Glycosides & \\
\hline & a)Borntrager test & - \\
\hline & b)Kellerkilliani test & + \\
\hline 5. & Test for Sapponins & \\
\hline & a)Froth test & + \\
\hline & b)Lead acetate test & + \\
\hline 6. & Test for Tannins & \\
\hline & a)Ferric chloride test & - \\
\hline & b)Lead acetate test & + \\
\hline 7. & Test Terpenoids & \\
\hline & a)Salkowski test & - \\
\hline 8. & Test for Protein & \\
\hline & a)Ninhydrin test & - \\
\hline & b)Biuret test & + \\
\hline 9. & Test for Anthroquinone & \\
\hline & a)Ammonia test & - \\
\hline & & \\
\hline
\end{tabular}

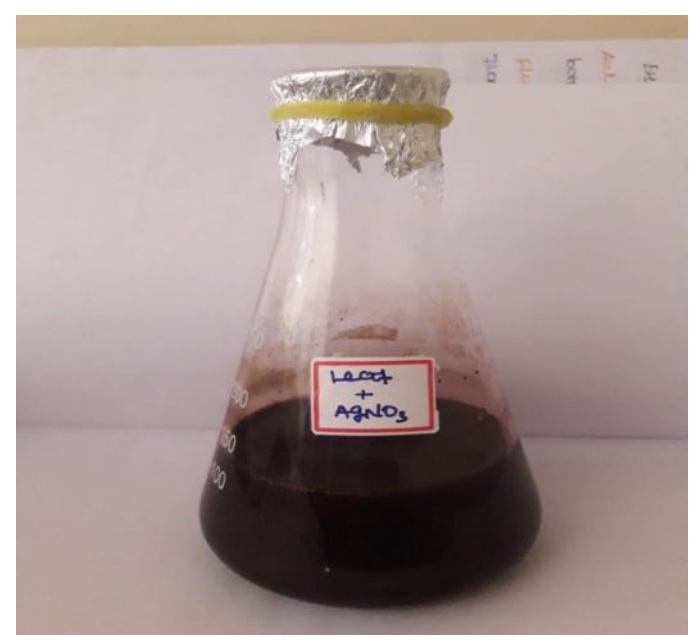

Figure 1 Formation of Ag-NPs synthesis using Persea americana extract 


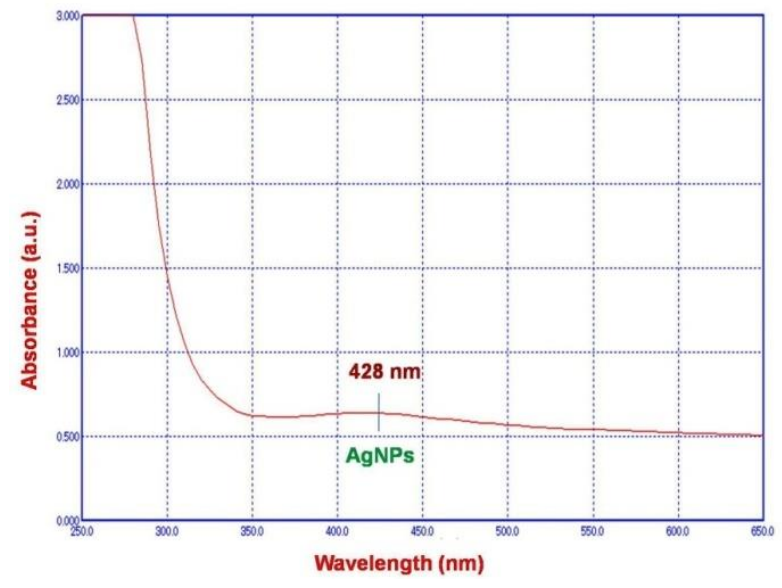

Figure 2 UV - Vis spectrophotometer of Ag-NPs using Persea americana extract.

\subsection{X- ray diffraction (XRD) Analysis}

XRD was used to analysis the purity, crystalline nature of the AgNPs using Persea americana leaves extract. Green synthesized AgNPs show diffraction peaks at $2 \theta$ (in degrees) $38.36^{\circ}, 46.39^{\circ}, 64.84^{\circ}$ $77.49^{\circ}$ and $86.05^{\circ}$ can be indexed to the (111), (200), (220), (311) and (222) planes of the face centered cubic (fcc) silver respectively, as shown in the Fig 3.

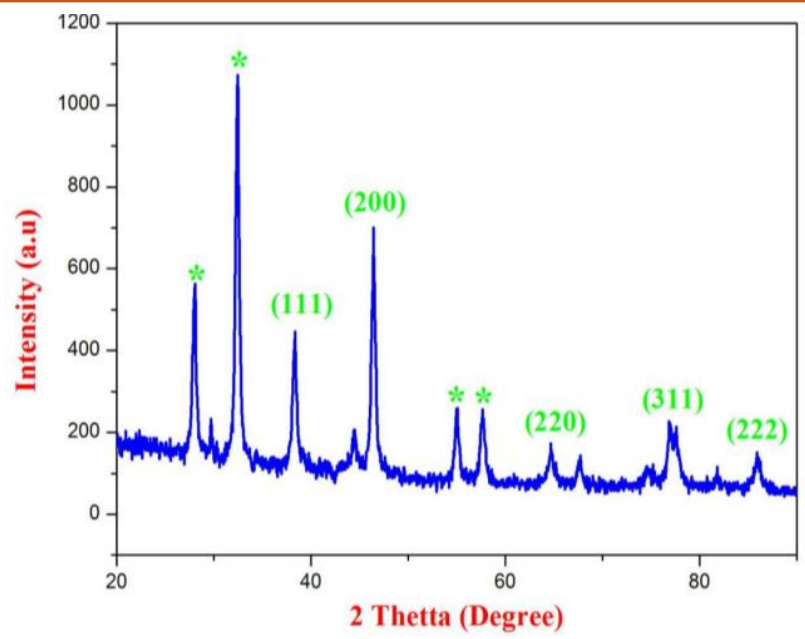

Fig. 3. X-ray diffraction pattern of prepared AgNPs using Persea americana leaves extract.

\subsection{SEM analysis of silver nanoparticles}

Morphological character and size details of the green synthesized silver nanoparticles using the leaf extract Persea americana were presented by SEM images. The size of the nanoparticles was investigated from the SEM image in the ranges of 40-92 nm Fig 4. The figure indicates, that the synthesized silver nanoparticles were well separated showing no agglomeration.
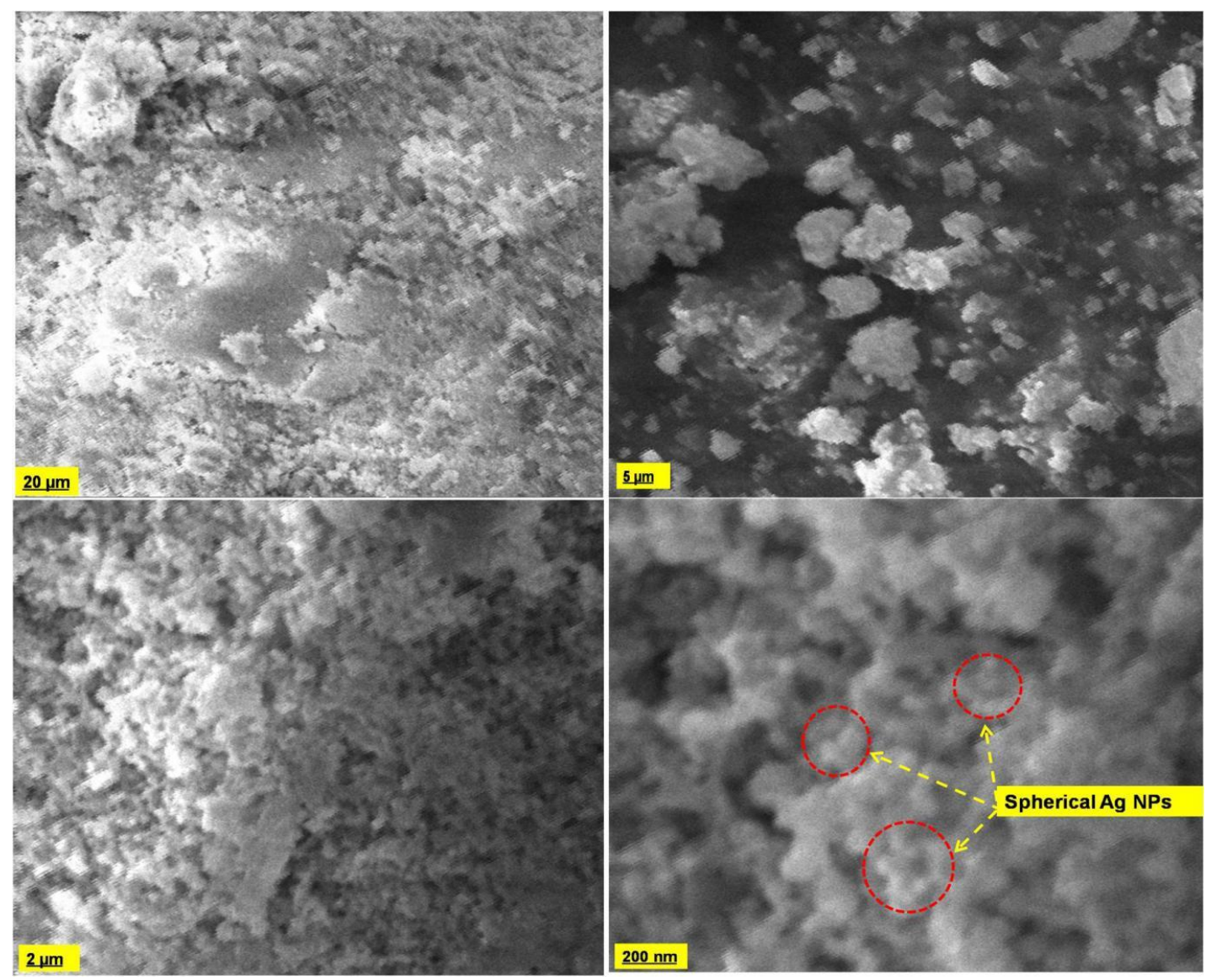

Figure 4 SEM Image of silver nanoparticles synthesized by Persea americana 
This size difference in the nanoparticles is due to the presence of proteins or other bio-molecules from extract Persea americana, which was bound in the surface of the nanoparticles and also the result showed that the green synthesized silver nanoparticles were of spherical in shape.

\subsection{FTIR analysis}

FTIR measurements were carried out to recognize the presence of functional groups in the biomolecules, which is responsible for the bio reduction of silver nanoparticles. From the present investigation, FTIR spectrum shows five absorption bands at 1602, $1381,1050,846$, and $646 \mathrm{~cm}^{-1}$ indicating the presence of capping agent with the nanoparticles, the pictorial spectrum was presented in the Fig 5 . The bands at $1602 \mathrm{~cm}^{-1}$ corresponds to carbon-carbon (CC) [14] and carbonyl stretching $(\mathrm{C}=\mathrm{O})$ stretching vibrations. A strong peak was observed at $1381 \mathrm{~cm}^{-1}$ and a medium band at $1050 \mathrm{~cm}^{-1}$ corresponds to $\mathrm{CN}$ vibrations indicate the presence of amine group in protein. Two weak band were observed at 846 and $646 \mathrm{~cm}^{-1}$ were corresponds to hydroxyl $(\mathrm{OH})$ and $\mathrm{C}-\mathrm{Cl}$ vibrations point out the presence of alkyl group respectively. From the analysis of FT-IR study the above mentioned functional group have stronger ability to bind metal, indicating that the proteins could possibly for the metal nanoparticles (i.e. capping of $\mathrm{AgNO}_{3} \mathrm{NPs}$ )

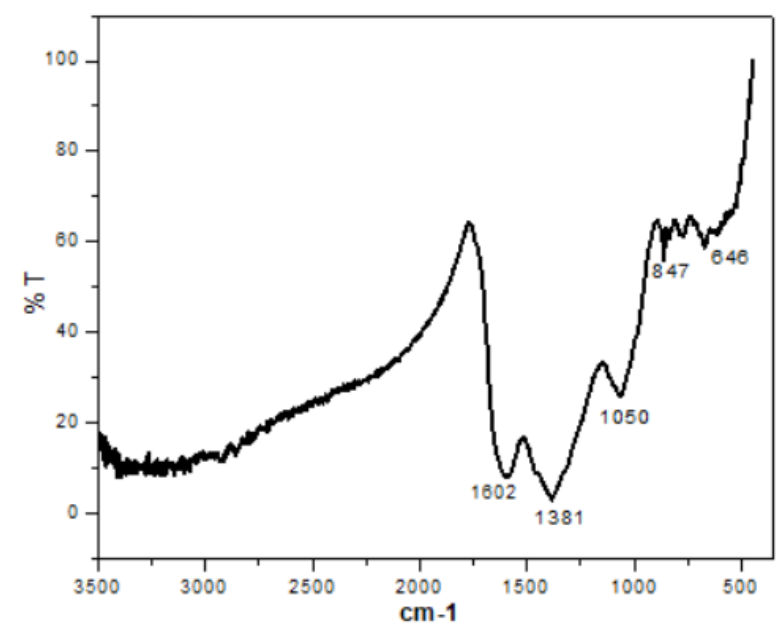

Figure 5 FTIR spectra of silver nanoparticle synthesized by Persea America

\subsection{Antibacterial study}

The antibacterial activity of green synthesized silver nanoparticles were tested by well diffusion method [15] against pathogenic bacteria such as Lactobacillus sp, Staphylococcus aureus, Streptococcus mutans, Klebsiella pneumoniae, Serratia marcescens, and Escherichia coli. The results were presented in the
Table 2. The silver nanoparticle showed maximum zone of inhibition against Streptococcus mutans ranged from $10 \pm 0.2$ to $15 \pm 0.6$ followed by Escherichia coli., Staphylococcus aureus, Lactobacillus, Klebsiella pneumonia and Serratia marcescens. The maximum zone of inhibition in Streptococcus mutansshows that the synthesized silver nanoparticles have the ability to control the infections such as wound and skin infection, sepsis and endocarditis The zone of inhibition was increased by increasing concentrations which was shown in the Fig 6 .

\subsection{Antifungal study}

In recent days, fungal infections are significantly increased, we use wide range of antimicrobials to treat fungal infections. The most common fungal species to cause infection is Candida $s p$. The antifungal activity of synthesized silver nanoparticles was tested against pathogenic fungi such as Aspergillus niger, Aspergillus flaves, Candida albicans and Fusarium $s p$, the result were presented in the Table 3 and shown in the Fig 7. The crude extracts of Persea americana showed maximum zone of inhibition against Fusarium $s p$ ranged from $10 \pm 0.3$ to $14 \pm 0.2$ followed by Aspergillus flaves, Aspergillus niger and Candida albicans.
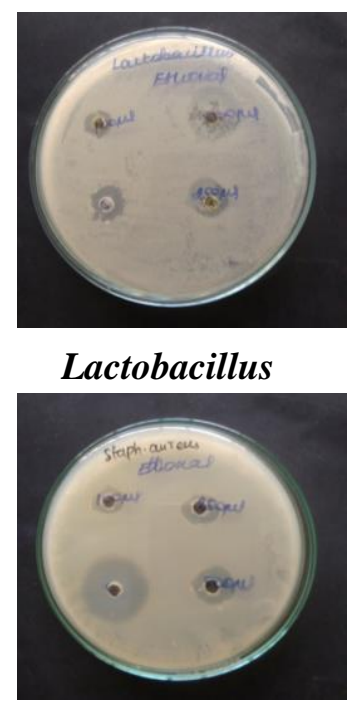

Staphylococcus aureus

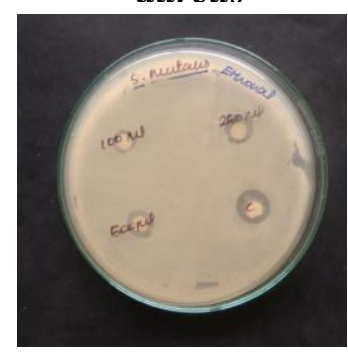

Streptococcus

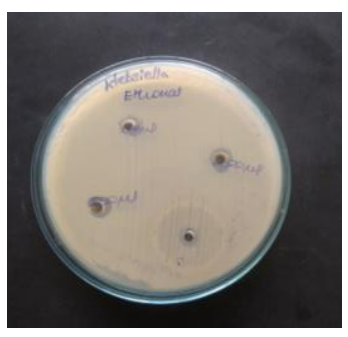

Klebsiellapneumoniae

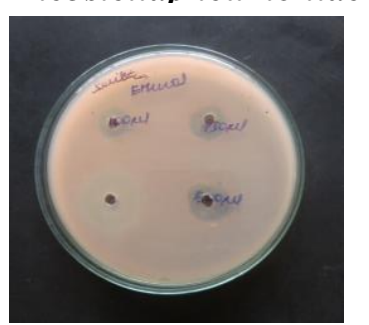

Serratiamarcesce

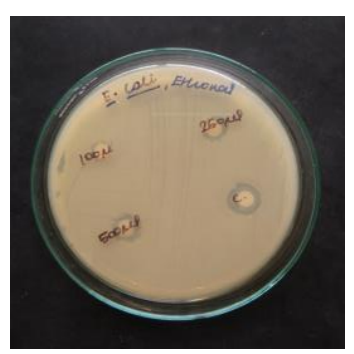

E-coli
Figure 6 Antibacterial activity of Ag-NPs synthesized using Persea americana extracts 
Table 2 Antibacterial activity of synthesized AgNPs of Persea americana by well diffusion method

\begin{tabular}{|l|c|c|c|c|}
\hline \multirow{2}{*}{$\begin{array}{l}\text { TESTED } \\
\text { ORGANISM }\end{array}$} & \multicolumn{4}{|c|}{ Zone of inhibition (mm) } \\
\cline { 2 - 5 } & $\mathbf{5 0} \mathbf{\mu L}$ & $\mathbf{1 0 0} \mathbf{\mu L}$ & $\mathbf{1 5 0} \boldsymbol{\mu L}$ & Control \\
\hline Lactobacillus sp & $9 \pm 0.2$ & $10 \pm 0.4$ & $13 \pm 0.2$ & $15 \pm 0.6$ \\
\hline Staphylococcus aureus & $9 \pm 0.6$ & $11 \pm 0.2$ & $14 \pm 0.4$ & $20 \pm 0.2$ \\
\hline Streptococcus mutans & $10 \pm 0.2$ & $12 \pm 0.4$ & $15 \pm 0.6$ & $25 \pm 0.4$ \\
\hline Klebsiellapneumonia & $7 \pm 0.1$ & $9 \pm 0.3$ & $12 \pm 0.4$ & $22 \pm 0.6$ \\
\hline Serratia marcescens & $6 \pm 0.2$ & $10 \pm 0.4$ & $11 \pm 0.2$ & $20 \pm 0.6$ \\
\hline Escherichia coli & $8 \pm 0.1$ & $11 \pm 0.3$ & $14 \pm 0.6$ & $24 \pm 0.4$ \\
\hline
\end{tabular}

Table 3 Antifungal activity of synthesized AgNPs of Persea americana by well diffusion method

\begin{tabular}{|c|c|c|c|c|}
\hline \multirow{2}{*}{$\begin{array}{c}\text { TESTED } \\
\text { ORGANISM }\end{array}$} & $\mathbf{4}$ Zone of inhibition (mm) \\
\cline { 2 - 5 } & $\mathbf{1 0 0} \boldsymbol{\mu L}$ & $\mathbf{2 5 0} \boldsymbol{\mu} \mathbf{L}$ & $\mathbf{5 0 0} \boldsymbol{\mu L}$ & Control \\
\hline Aspergillus niger & $7 \pm 0.2$ & $9 \pm 0.4$ & $12 \pm 0.2$ & $20 \pm 0.6$ \\
\hline Aspergillus flaves & $9 \pm 0.1$ & $11 \pm 0.3$ & $13 \pm 0.4$ & $16 \pm 0.2$ \\
\hline Candida albicans & $8 \pm 0.2$ & $9 \pm 0.4$ & $11 \pm 0.3$ & $15 \pm 0.2$ \\
\hline Fusarium $s p$ & $10 \pm 0.3$ & $12 \pm 0.4$ & $14 \pm 0.2$ & $25 \pm 0.6$ \\
\hline
\end{tabular}

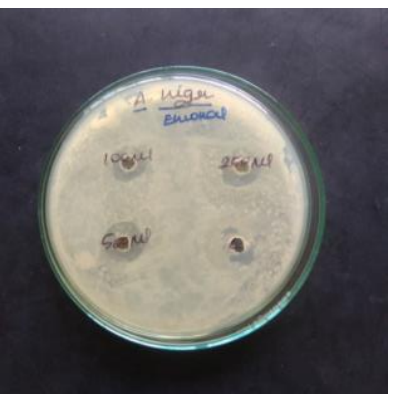

Aspergillusniger

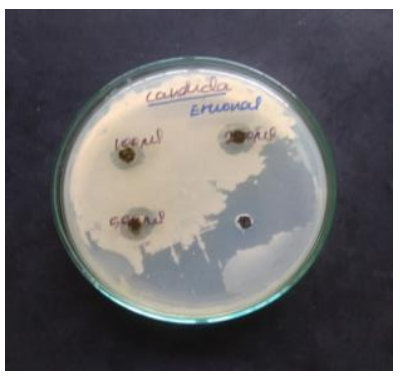

Candida albicans

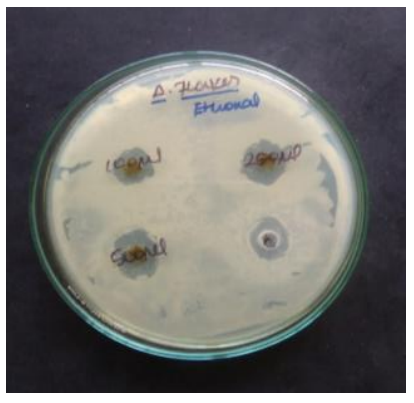

Aspergillusflavus

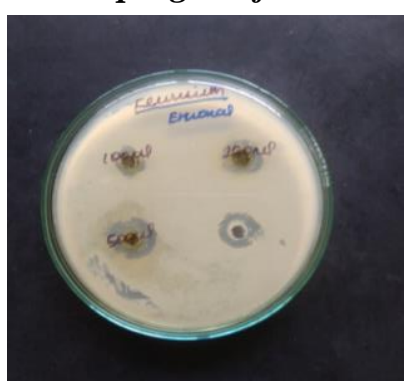

Fusarium sp

Figure 7 Antifungal activity of bio-reduced Ag-NPs synthesized using Persea americana extracts

\section{Conclusion}

Medicinal plants have many biological activities such as antidiuretic, anti-inflammatory, antiviral, antibacterial, antianalgesic, anti-oxidant, anti-abortifiecient due to the presence of secondary metabolites. The present study provides evidence that ethanolic extract of Persea americanacontains many secondary metabolites, used to treat diseases. The bio reduction of silver ions by ethanolic leaf extract of Persea americana also confirms the presence of flavonoids and alkaloids, the synthesized nanoparticles was characterized by UV-Vis spectroscopy, XRD, SEM and FTIR analysis. A simple eco-friendly synthesized nanoparticle shows prominent antimicrobial activity against bacterial and fungal species may be used for microbial associated diseases.

\section{References}

[1] A. Faris, Review on avocado value chain in Ethiopia, Industrial Engineering Letters, 6(3) (2016) 33-40.

[2] D.A. Akinpelu, O.A. Aiyegoro, O.F. Akinpelu and A.I. Okoh, Stem bark extract and fraction of Persea americana (Mill.) exhibits bactericidal 
activities against strains of Bacillus cereus associated with food poisoning, Molecules, 20(1) (2015) 416-429.

\section{https://doi.org/10.3390/molecules20010416}

[3] O.O. Adeyemi, S.O. Okpo and O.O. Ogunti, Analgesic and anti-inflammatory effects of the aqueous extract of leaves of Persea americana Mill (Lauraceae), Fitoterapia, 73(5) (2002) 375380.https://doi.org/10.1016/S0367326X(02)00118-1

[4] J.A. Ojewole, Antinociceptive, anti-inflammatory and antidiabetic properties of Hypoxis hemerocallidea Fisch. \& CA Mey.(Hypoxidaceae) corm ['African Potato'] aqueous extract in mice and rats, Journal of Ethnopharmacology, 103(1) (2006) 126-134.

\section{https://doi.org/10.1016/j.jep.2005.07.012.}

[5] J.A. Ojewole and G.J. Amabeoku, Anticonvulsant effect of Persea americana Mill (Lauraceae)(Avocado) leaf aqueous extract in mice, Phytotherapy Research: An International Journal Devoted to Pharmacological and Toxicological Evaluation of Natural Product Derivatives, 20(8) (2006) 696-700.

https://doi.org/10.1002/ptr.1940

[6] J.O. Adeboye, M.O. Fajonyomi, J.M. Makinde and O.B. Taiwo, A preliminary study on the hypotensive activity of Persea americana leaf extracts in anaesthetized normotensive rats, Fitoterapia, 70(1) 1999 15-20.

https://doi.org/10.1016/S0367-326X(98)00015-X

[7] M. Yasir, S. Das and M.D. Kharya, The phytochemical and pharmacological profile of Persea americana Mill, Pharmacognosy reviews, 4(7) (2010) 77.

https://dx.doi.org/10.4103\%2F0973-7847.65332

[8] A.A. Paul and F.J. Adewale, Data on optimization of production parameters on Persea Americana (Avocado) plant oil biodiesel yield and quality, Data in brief, 20 (2018) 855-863.

\section{https://doi.org/10.1016/j.dib.2018.08.064}

[9] A.P. De Almeida, M.M.F.S Miranda, I.C. Simoni, M.D. Wigg, M.H.C. Lagrota, and S.S. Costa, Flavonol monoglycosides isolated from the antiviral fractions of Persea americana (Lauraceae) leaf infusion, Phytotherapy Research: An International Journal Devoted to Pharmacological and Toxicological Evaluation of Natural Product Derivatives, 12(8) (1988) 562-
567.

[10] M.D. Wigg, A.A. Al-Jabri, S.S. Costa, E. Race, B. Bodo, and J.S. Oxford, In-Vitro Virucidal and Virustatic anti HIV-1 Effects of Extracts from Persea Americana Mill,(Avocado) Leaves, Antiviral Chemistry and Chemotherapy, 74) (1996) 179-183.

https://doi.org/10.1177\%2F095632029600700401

[11] B.I. Brai, A.A. Odetola, and P.U. Agomo, Hypoglycemic and hypocholesterolemic potential of Persea americana leaf extracts, Journal of medicinal food, 10(2) (2007) 356-360.

https://doi.org/10.1089/jmf.2006.291

[12] J.B. Herborne, Phytochemical methods, A guide to modern techniques of plant analysis, (1973) pp.5-11. Springer Netherlands.

https://doi.org/10.1007/978-94-009-5921-7

[13] A.K. Keshari, R. Srivastava, P. Singh, V.B. Yadav and G. Nath, Antioxidant and antibacterial activity of silver nanoparticles synthesized by Cestrum nocturnum, Journal of Ayurveda and integrative medicine, 11(1) 2020 37-44.

https://doi.org/10.1016/j.jaim.2017.11.003.

[14] A. Ram Kumar, S. Selvaraj, K.S. Jayaprakash, S. Gunasekaran, S. Kumaresan, J. Devanathan, K.A. Selvam, L. Ramadass, M. Mani and P. Rajkumar, Multi-spectroscopic (FT-IR, FTRaman, 1H NMR and 13C NMR) investigations on syringaldehyde. Journal of Molecular Structure, 2020 p.129490.

https://doi.org/10.1016/j.molstruc.2020.129490.

[15] K. Kolanjinathan, K. A. Selvam, J. Devanathan , S. Selvaraj, A. Ram kumar and S. Sureshkumar, Screening of antimicrobial activity of Avicennia marina plant against clinical pathogens, Chemistry Reports, 2(1) (2019) 27-34.

\section{Acknowledgement}

The authors thank to Thiruvalluvar University, Serkkadu, Vellore-632 115, Tamil Nadu, India, for recording UV-Visible spectroscopy measurement. The authors are thankful to Saveetha Dental College and Hospital Velappanchavadi, Chennai-600 077 Tamil Nadu, India, for recording FT-IR and XRD spectral measurements. Also, the authors are thankful to National College, Karumandapam, Tiruchirappalli-620 001 Tamil Nadu, India, for recording SEM measurements.

\section{Funding}

No funding was received for conducting this study. 


\section{Authors Contribution}

Conceptualization, methodology, manuscript preparation, review and editing (KAS); Manuscript Review and Editing (MS, JD, KK, AR, SS, LR). All the authors have read and approved the manuscript.

\section{Ethics Approval}

Approval was sought and granted by the Departmental Ethics Committee.

\section{Conflict of interest}

The authors have no conflicts of interest to declare that they are relevant to the content of this article.

\section{About The License}

(C) The author(s) 2020. The text of this article is open access and licensed under a Creative Commons Attribution 4.0 International License 